rs10500804 (OR 1.85, p = 0.02); AG genotype for CYP2R1 SNP rs10766197 (OR 1.82, $\mathrm{p}=0.03)$; AA genotype for VDR SNP rs7975232 (OR 2.15, p = 0.02).

Conclusions Over half of participating asthma patients were vitamin D deficient. Obesity, winter sampling, fair skin, and SNP in DBP, CYP2R1 and VDR genes were risk factors for deficiency. Caucasian ethnicity, sun seeking behaviour, modest daily supplement doses and recent tanning bed use were protective.

\section{P49 CAN THE ASTHMA CONTROL QUESTIONNAIRE (ACQ) AND/OR THE BLOOD EOSINOPHIL COUNT ACCURATELY DETECT SPUTUM EOSINOPHILIA?}

JR Anderson, DB Hodgson, EE Wilson, TW Harrison, DE Shaw. Nottingham Respiratory Research Unit, Nottingham, UK

\subsection{6/thoraxjnl-2014-206260.190}

Induced sputum differential cell counts provide important information about airway inflammation and future risk in asthma, but are not universally available. We set out to ascertain the sensitivity and specificity of the Juniper Asthma Control Questionnaire (ACQ) and/or the peripheral blood eosinophil count to detect a sputum eosinophil count $>3 \%$.

Methods We performed a retrospective, cross-sectional study of 165 subjects with asthma, aged 18-80, prescribed as-required bronchodilators, long-acting $\beta$-agonists, $0-4000$ mcg inhaled beclometasone diproprionate equivalent or maintenance oral steroids (0-20 mg prednisolone) from our database. Current smokers were excluded. Spirometry, FeNO at $50 \mathrm{ml}$ flow, sputum induction, Asthma Control Questionnaire (ACQ) and blood eosinophils (BEos) were recorded.

Induced sputum eosinophils (SEos) defined eosinophilic (EA, SEos $\geq 3 \%$ ) and non-eosinophilic (NEA, SEos $<3 \%$ ) groups. BEos, SEos and FeNO were $\log _{10}$ transformed and groups were compared with t-tests or Mann-Whitney-U using STATA and GraphPad. Receiver operating characteristic (ROC) curves determined cut-points of ACQ and BEos that identified SEos $\geq 3 \%$, and these were tested retrospectively in a second population of adults with asthma ( $\mathrm{n}=48,40 \% \mathrm{EA}$, mean $\mathrm{FEV}_{1} 82 \%$ predicted).

Results The $31 \%$ with EA had a lower $\mathrm{FEV}_{1} \%$ predicted and $\mathrm{FEV}_{1} / \mathrm{FVC}$ ratio, a higher FeNO, BEos and ACQ compared to NEA (Table 1). There was a significant correlation between ACQ and sputum eosinophils (Pearson r 0.32, $\mathrm{p}<0.0001$ ).

The optimal cut-points of ACQ and BEos identifying a SEos of $3 \%$ were an ACQ $>1.57$ (sensitivity 55\%, specificity 78\%) and BEos $\geq 0.22 \times 10^{9} / \mathrm{L}$ (sensitivity $84 \%$ and specificity $68 \%$ ) respectively. Individuals with both ACQ of $\geq 1.57$ AND a BEos of $\geq 0.22$ the sensitivity was $45 \%$ and specificity of $100 \%$ for a SEos of $3 \%$.

Testing in the second population the ACQ $\geq 1.57$ had a sensitivity $47 \%$ and specificity $86 \%$ for SEos $>3 \%$ while BEos $\geq 0.22$ had sensitivity $68 \%$ and specificity $45 \%$. The combination of ACQ $\geq 1.57$ AND BEos $\geq 0.22$ had a lower sensitivity of $37 \%$

\begin{tabular}{|c|c|c|c|c|}
\hline & All & Sputum eosinophils $<3 \%$ & Sputum eosinophils $>3 \%$ & $\mathrm{p}$ value \\
\hline Number observations & $\mathrm{n}=165$ & $n=114(69 \%)$ & $\mathrm{n}=54(31 \%)$ & \\
\hline Age (years) & $56.2 \pm 13.4$ & $57.4 \pm 13.75$ & $53.5 \pm 12.2$ & 0.081 \\
\hline \multicolumn{5}{|l|}{ Gender } \\
\hline Male $n$ (\%) & $81(49.1 \%)$ & $53(46.5 \%)$ & $28(54.9 \%)$ & \\
\hline Female $n(\%)$ & $84(50.9 \%)$ & $61(53.5 \%)$ & $23(45.1 \%)$ & - \\
\hline FEV $_{1}$ (Litres) & $2.39 \pm 0.85$ & $2.46 \pm 0.87$ & $2.23 \pm 0.79$ & 0.12 \\
\hline $\mathrm{FEV}_{1} \%$ predicted & $80.5 \pm 20.7$ & $83.54 \pm 19.4$ & $73.7 \pm 23.2$ & $0.005^{*}$ \\
\hline FVC (Litres) & $3.46 \pm 1.03$ & $3.49 \pm 1.06$ & $3.36 \pm 0.95$ & 0.46 \\
\hline FVC $\%$ predicted & $95.1 \pm 18.8$ & $96.9 \pm 17.5$ & $91.0 \pm 21.09$ & 0.062 \\
\hline$F E V_{1} / F V C$ & $68.7 \pm 9.9$ & $70 \pm 9.8$ & $65.7 \pm 9.4$ & $0.008^{*}$ \\
\hline Body-mass index $\left(\mathrm{Kg} / \mathrm{m}^{2}\right)^{+}$ & $28.6 \pm 5.1$ & $28.8 \pm 4.0$ & $26.9 \pm 3.0$ & 0.54 \\
\hline \multicolumn{5}{|l|}{ History of smoking } \\
\hline (Pack-years) & 0 & 0. & 0 & \\
\hline Median (range) & $(0,20)$ & $(0,20)$ & $(0,15)$ & $0.87^{\dagger}$ \\
\hline Daily inhaled corticosteroid dose (Becolmetasone diproprionate equivalent [mcg/day]) & 400 & 400 & 800 & \\
\hline Median (range) & $(0,3200)$ & $(0,3200)$ & $(0,3200)$ & $0.05^{\dagger}$ \\
\hline Oral Prednisolone & 0 & 0 & 0 & \\
\hline Median (range) & $(0,20)$ & $(0,15)$ & $(0,20)$ & $\cdot$ \\
\hline Juniper $A C Q^{\#}$ score & $1.4 \pm 1.0$ & $1.1 \pm 0.9$ & $1.9 \pm 1.2$ & $<0.001^{*}$ \\
\hline Exhaled nitric oxide FeNO at 50ml flow (ppb) Geometric mean (95\% Cl) & $25.7(22.9,28.8)$ & $20.0(17.8,22.9)$ & $44.7(35.5,56.23)$ & $<0.001^{*}$ \\
\hline \multicolumn{5}{|l|}{ Sputum differential eosinophil count \% } \\
\hline Geometric mean $(95 \%$ Cl) & $1.24(0.95,1.62)$ & $0.47(0.39,0.55)$ & $11.0(8.3,14.13)$ & $<0.001^{*}$ \\
\hline \multicolumn{5}{|l|}{ Blood eosinophils $\left(\times 10^{9} / L\right)$} \\
\hline Geometric mean & $0.24(0.22,0.28)$ & $0.19(0.18,0.21)$ & $0.43(0.36,0.5)$ & $<0.001^{*}$ \\
\hline $\begin{array}{l}\text { Arithmetic mean values reported as mean unless specified } \\
\pm \text { Standard deviation } \\
\text { Geometric means are reported with a } 95 \% \text { Confidence Interval (Cl) } \\
\text { The difference between means compared with } \mathrm{t} \text {-test unless specified with } \dagger \\
\text { \# Juniper Asthma Control Questionnaire- A validated questionnaire providing a numerical asses } \\
\text { to } 6 \text { (poorly controlled) } \\
\dagger \text { Mann-Whitney U } \\
{ }^{*} \mathrm{p}<0.05 \\
\mathrm{FEV}_{1} \text {. Forced expiratory volume in one second } \\
\text { FVC- Forced vital capacity } \\
\text { ppb- Parts per billion }\end{array}$ & ent of asthma con & over the preceding 7 days. & mean score ranges from 0 & controlled) \\
\hline
\end{tabular}


but a high specificity of $93 \%$ and could be useful to exclude rather than identify the presence of sputum eosinophilia.

Conclusion Combined testing using ACQ and BEos only identifies eosinophilia in 37\% and can't replace induced sputum, but may be useful to exclude sputum eosinophilia and prospective study is warranted.

\section{P50 DIFFICULT ASTHMA CLINICS: ARE THEY EFFECTIVE?}

I Macpherson, S Fielding, JG Douglas. Chest Clinic C, Aberdeen Royal Infirmary, Aberdeen, UK

\subsection{6/thoraxjnl-2014-206260.191}

Background "Difficult asthma" is defined as persistent symptoms and/or frequent exacerbations in patients with a diagnosis of asthma, despite treatment at step 4 or 5 of the BTS/SIGN guidelines ${ }^{1}$. "Difficult asthma" clinics have been set up in many UK hospitals, but there is no published evidence to suggest their effectiveness at reducing exacerbations or hospital admissions.

Aims To determine whether a regional difficult asthma clinic led to a reduction in prescription of oral steroid for exacerbations and a reduction in hospital admissions for asthma.

Methods A retrospective analysis of patients who attended this regional difficult asthma clinic between August 2009 and May 2013 was performed. Medical notes and GP letters were scrutinised to ascertain the number of hospital admissions two years before and two years after the first clinic appointment. For oral steroids, one year before and after was used. To compare these data Wilcoxon tests were used due to the skewed data.

Results For hospital admissions, data was available for 44 patients, mean (SD) age $44.2(14.1)$ and $66 \%$ female. The median (inter-quartile range (IQR)) number of hospital admissions in the two years prior to clinic was $2(0,3)$ compared to 0 $(0,1)$ in the two years following clinic visit $(p=0.014)$. Oral steroid prescription data was available for 54 patients, mean (SD) age 43.5 (14.4), 70\% female. The median (IQR) number of oral steroid courses required in the year prior to first clinic appointment was $6(3.75,10)$, which reduced to $2(0,4)$ in the year after first appointment $(\mathrm{p}<0.001)$.

Conclusion Our regional difficult asthma clinic significantly reduced both hospital admissions for asthma two years after first clinic appointment and number of oral steroid prescriptions one year after first clinic appointment. This study, although small, highlights the benefit of such clinics to patients and the potential for the reduction in use of NHS resources. They should be encouraged in all major centres.

\section{REFERENCE}

1 Prys-Picard CO, Campbell SM, Ayres JG, Miles JF, Niven RM. Consensus Difficult Asthma Consortium UK. Defining and investigating difficult asthma: developing quality indicators. Respiratory Medicine 2006;100(7):1254-61

\section{P51 BARRIERS AND FACILITATORS TO EFFECTIVE SELF- MANAGEMENT OF ASTHMA - A SYSTEMATIC REVIEW AND THEMATIC SYNTHESIS}

SE Kirby', C Miles ${ }^{2}$, E Arden-Close ${ }^{1}$, L Yardley ${ }^{2}$, A Bruton ${ }^{3}$, M Hankins ${ }^{4},{ }^{5}$ DM Thomas. ${ }^{1}$ Department of Psychology, University of Southampton, UK, NIHR Southampton Respiratory Biomedical Research Unit, UK; ${ }^{2}$ Department of Psychology, University of Southampton, UK; ${ }^{3}$ Faculty of Health Sciences, University of SouthamptonUK, NIHR Southampton Respiratory Biomedical Research Unit, UK; ${ }^{4}$ Real-World Evidence Solutions, IMS Health UK; ${ }^{5}$ Department of Primary Medical Care, University of Southampton, UK, NIHR Southampton Respiratory Biomedical Research Unit, UK

10.1136/thoraxjn-2014-206260.192
Introduction and objectives Self-management is an established approach to controlling asthma, recommended in guidelines. Despite the reported effectiveness of self-management, its promotion, uptake and use among patients, carers, and health-care professionals remain low. We conducted a systematic review and thematic synthesis of qualitative research into self-management in adults, children and adolescents with asthma. Our objective was to identify the perceived barriers and facilitators associated with reduced or improved effectiveness of asthma selfmanagement.

Method Electronic databases (Medline, EMBASE, AMED, CINAHL, and PsycINFO; 1996 - August 2013) and British Thoracic Society guidelines were searched for qualitative literature that explored factors relevant to facilitators and barriers to uptake, adherence, or outcomes of self-management in adults, children and adolescents with asthma. We assessed the methodological strengths of the studies using the Critical Appraisal Skills Programme (CASP) tool for qualitative studies, and conducted a thematic synthesis of included studies.

Results Of the 1532 studies initially identified, 34 papers were included in the review. Thematic synthesis identified 10 overarching themes (Figure 1) which suggest that barriers and facilitators of self-management included the perceived quality of the relationship between health-care professionals and patients, the perceived adequacy of education around self-management and medications, and positive and negative beliefs about asthma with regards to self-management and existing interventions. Self-management could also be helped or hindered by the amount and type of social support and perceived ease of access to healthcare. In addition, having a co-morbidity, mood/anxiety problems, and encountering professional barriers within the health care system (such as consultation time and access to lung function testing), are perceived to hinder successful self-management of asthma.

Conclusion Perceived barriers and facilitators occur at the level of individuals with asthma (and carers), health-care professionals, and organisations. These findings contribute to our understanding of why existing self-management interventions may not always be effective, and can be used to inform future study into areas where further intervention may improve the adoption of self-management of asthma. For example, future work could include addressing patient and carer beliefs in educational interventions and decisions involving treatment, or greater use of pharmacist educators, patient advocates, and technological interventions.

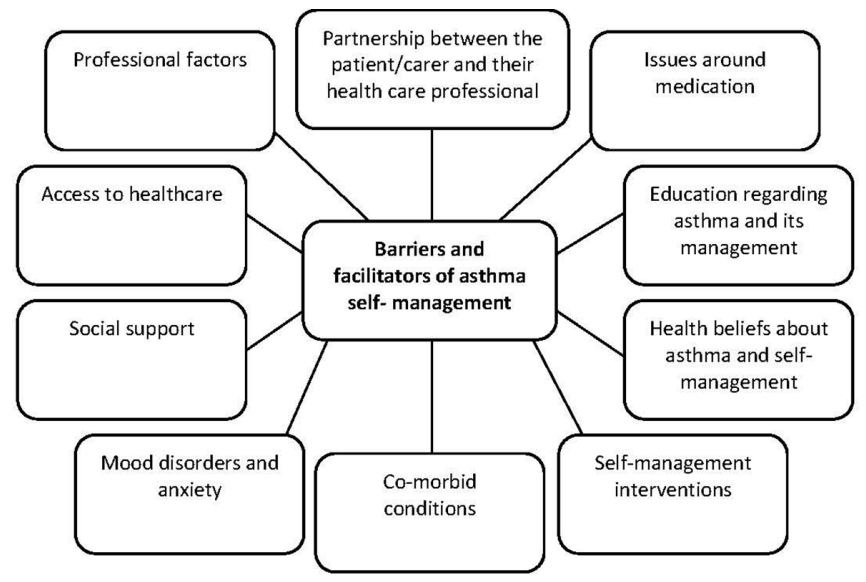

Abstract P51 Figure 1 Overarching themes identified during thematic synthesis 